\title{
THE EFFECTIVENESS OF THE LEVEL OF EXERCISE IN RATING PERCEIVED EXERTION (RPE) METHOD FOR SENIOR CITIZENS
}

\author{
Nobuo Takeshima*, Fumio Kobayashi**, Katsuhiro Sumi**, \\ TAKEMASA Watanabe** and TAKashi Kato***
}

\begin{abstract}
The purpose of this study was to measure the effectiveness of RPE on exercise intensity for senior citizens. A maximum workload test was administered with the use of a bicycle ergometer on older male and female subjects. The results of our study can be summarized as follows :

1. Two trials were performed on separate days. A high correlation coefficient for the first trial and the second trial was found. The reliability for the male group was $r=0.76$ $(p<0.01)$ and that for the female group $r=0.90(p<0.01)$.

2. A correlation range of $r=0.55 \sim 0.79$ ( $p(0.01)$ was found for RPE and physiological exercise intensity (which includes oxygen intake and heart rate). A higher result was found when the relative value was used in the analysis of the oxygen intake and the heart rate instead of the absolute value.

3. Significant correlation coefficients of $r=0.63 \sim 0.64(p<0.01)$ were found for RPE and the work load in terms of watt units.

4. The majority of the physiological variables were statistically determined ; however, there were no correlations between RPE and systolic blood pressure.

In conclusion, based on our study, we have found that RPE and $\mathrm{HR} ; \mathrm{RPE}$ and $\% \dot{\mathrm{V}}_{2} \max$ : RPE and watts grouped individually had a high correlation for effectiveness. The only exception in our study was the RPE and the blood pressure group because no correlation was found overall. Therefore, the overall effectiveness of RPE was proven to be quite sensitive even for senior citizens, and as a result RPE can be utilized when exercise is prescribed for evaluatory measurement in senior citizens.
\end{abstract}

(Jpn. J. Phys. Fitness Sports Med. 1988, $37: 254-262$ )

key words : Senior Citizens, ergometer test, RPE.

\section{Introduction}

In the realm of exercise prescription, exercise intensity has already been established as a necessity. And within exercise intensity, the most widely used physiological variables are the heart rate and oxygen consumed during the exercise. Until now, the evaluator measurement for exercise intensity has been a scale called the Rating of Perceived Exertion or RPE for short.

As early as 1967, Borg $^{21}$ had developed the
RPE scale as a psychophysical category scale. He devised a fifteen point graded scale that ranged from a scale point of six for very very light to a scale point of twenty for very very hard. Other studies have shown that within the RPE scale, a linear relationship between the heart rate and other physiological exercise intensity or in other work load in terms of exercise intensity is evident. It has also been noted that by using Borg's scale. It is possible to calculate an estimation of the heart rate and other physiological variables. As an example,

\footnotetext{
*名古屋市立大学 College of General Education, Nagoya City University, Mizuho-cho, Mizuho-ku, Nagoya, Japan 467.

**愛知医科大学 Department of Hygiene, Aichi Medical University.

***要知医科大学 Department of Public Health, Aichi Medical University.
} 
if a young subject is tested, his graded point on the RPE scale can be multiplied simply by ten and an estimation for the subject's heart rate can be obtained. According to Borg along with Sidney \& Shepard ${ }^{\text {) }}$, the percentage of oxygen consumed $\left(\% \dot{\mathrm{V}}_{2} \max \right)$ in relation with RPE has the same linear coefficient in young or older subjects. Yet, Tokuda et al. ${ }^{10)}$ reported that there was indeed a difference between the two aged groups. In the senior citizen group, the maximum heart rate decreases during the exercise ; therefore, the correlation that a single RPE scale could be used for both age groups is very doubtful. Tokuda et al. ${ }^{3)}$ devised a modified version of Borg's RPE scale which can be used to meet the needs of senior citizen subjects. This modified version was partially due to the decrease in the maximum heart rate, but also because of other physiolog. ical functions' responses (i. e., blood pressure). The responses of a younger group would be different overall from the responses of a much older group. Therefore, with the revised RPE scale, a closer estimation of the actual responses from senior citizens can be found. Since Tokuda et al.'s revised scale has not been standardized in our field, we feel that another closer look into the differences of the Senior Citizens should be reviewed.

The purpose of this study is to determine if RPE is effective in rating the exercise intensity of older subjects. In addition, we attempt to observe other physiological factors that may effect the results from the RPE scale. In order to measure and evaluate the exercise intensity a bicycle ergometer was utilized for a maximum load test. With the bicycle ergometer, we determine if there is an effectiveness of RPE and if there is a relationship between a work load in terms of exercise intensity and RPE. From this data we also check into the following categories: (1) The reliability of RPE ; (2)The relationship between RPE, heart rate and oxygen consumption; and (3) The relationship between $\mathrm{RPE}$ and the variables within the subject group.

\section{Method}

\section{A. Subjects}

Five male senior citizens with a mean age of $70.3 \pm 2.5$ years and 12 female senior citizens with a mean age of $65.4 \pm 1.7$ years were tested. Before starting the test, all of the subjects underwent a thorough medical exam and were found to be free of any defects of the cardiovascular-respiratory system or the nervous system. The physical characteristics of the subjects are shown in Table 1.

Table 1. Physical characteristics of the subjects. (mean $\pm \mathrm{SD})$

\begin{tabular}{l|rccc}
\hline subjects & $\mathrm{n}$ & $\begin{array}{c}\text { Age } \\
(\text { years })\end{array}$ & $\begin{array}{c}\text { Height } \\
(\mathrm{cm})\end{array}$ & $\begin{array}{c}\text { Weight } \\
(\mathrm{kg})\end{array}$ \\
\hline male & 5 & $70.3 \pm 2.5$ & $160.6 \pm 4.1$ & $59.4 \pm 8.9$ \\
female & 12 & $65.4 \pm 1.7$ & $153.3 \pm 4.6$ & $51.7 \pm 5.9$ \\
\hline
\end{tabular}

\section{B. The level of Exercise Intensity}

For this test, a bicycle ergometer (Takeikiki) was utilized. The level of exercise intensity started at a 50 watts work load for the men and a work load of 40 watts for the women. After an initial four minutes, the work load was raised every four minutes at a rate of 10 watts. This was done three times. After 12 minutes, the work load was increased again for another 10 watts every minute until a maximum level was achieved. The level of exercise intensity was performed twice again in order to evaluate the test-retest Icorrelation reliability.

\section{Measuring Equipment}

During the actual exercise, the heart rate of the subjects was measured by a telemeter and for the blood pressure an automatic blood 
pressure cuff by the Nippon Colin (model STBP 680) was used. During the testing, the blood pressure was measured every minute. In order to measure the ventilation of the senior citizens a Douglas Bag was utilized. A rest time for the subjects consisted of a sitting down period of 5 minutes. The ventilation of the rest time was also measured. Ventilation was measured only during the last minute of the 4 minute period of exercise. This was continued for three 4 minute periods. After measuring ventilation for three 4 minute periods, the ventilation was then measured every minute for the one minute period of exercise, until total exhaustion. The concentration of oxygen and carbon dioxide was measured from the sample gas taken from the Douglas Bag with a Fukuda Industries (model BM-10) analyzer. The temperature of the room during the experiment was registered around 18 $23^{\circ} \mathrm{C}$. The atmospheric pressure was $758 \sim$ $762 \mathrm{mmHg}$. The subjects were instructed not to eat for at least two hours prior to the testing. Only an occasional drink of water was permitted.

\section{Definition}

RPE or rating of perceived exertion created originally by Borg was not used for this experiment. A Japanese translation of Borg's RPE scale by Onodera \& Miyashita $^{6)}$ was used instead. Since the subjects could not verbally communicate to the expermenter, due to the ventilation apparutus, the subjects simply pointed to a large chart to indicate to the experimenter their level of intensity.

\section{Results}

The chart in Fig. 1 represents the subject's two trials on the bicycle ergometer and also the correlation between the two trials. RPE-1 represents the first trial and RPE-2 represents
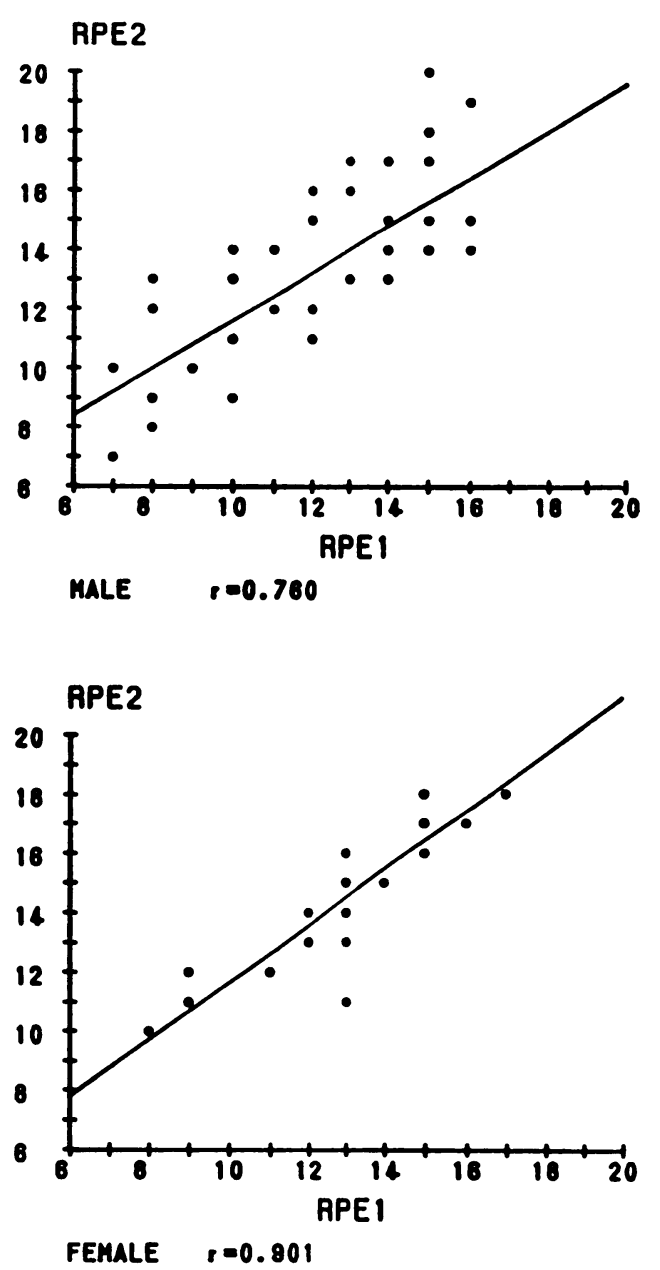

Fig. 1. The reliability of RPE,

the second trial. A high reliability coefficient was found for the men $(n=7)$ with a $r=0.76$, and for the women $(n=5)$ with a $r=0.90$.

The heart rate, $\% \dot{\mathrm{V}}_{2} \max$ and the work load exerted from the ergometer measured in watt units' results are shown in Fig. 2 to 4. The correlation between RPE and the heart rate; RPE and \% $\dot{\mathrm{V}}_{2} \max$ and $\mathrm{RPE}$ and watt units was significant at the 0.01 level. Table 2 reveals the correlation of RPE and the heart rate, $\% \dot{\mathrm{V}}_{2} \max$, and watt units. From looking at the regression equation, an estimation of each physiological variable within the RPE scale was obtainable. As an example to clarify 
HA (boets/min)

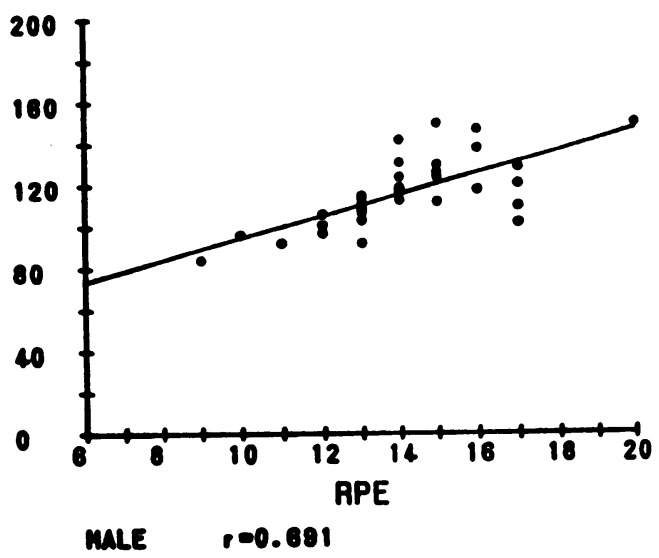

HA (boeto/min)

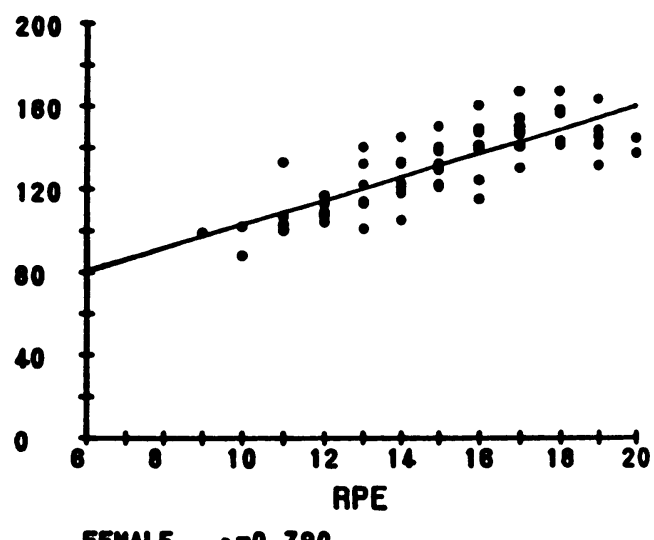

FEMALE $\quad p=0.780$

Fig. 2. The correlation between heart rate and RPE.

this point, if the level of exercise intensity from the RPE chart was 15 (or hard), the estimated $\% \mathrm{Vo}_{2} \max$ for the men would be $87.7 \%$ and for the women $82.0 \%$. The estimated heart rate for the men would be 121 beats per minute and 132 beat per minute for the women. For the watt units, the estimation for the men would be 87.0 watts and 64.1 watts for the women.

Table 3 represents the correlation coefficient for the various physiological variables such as heart rate, maximum heart rate, oxygen intake,
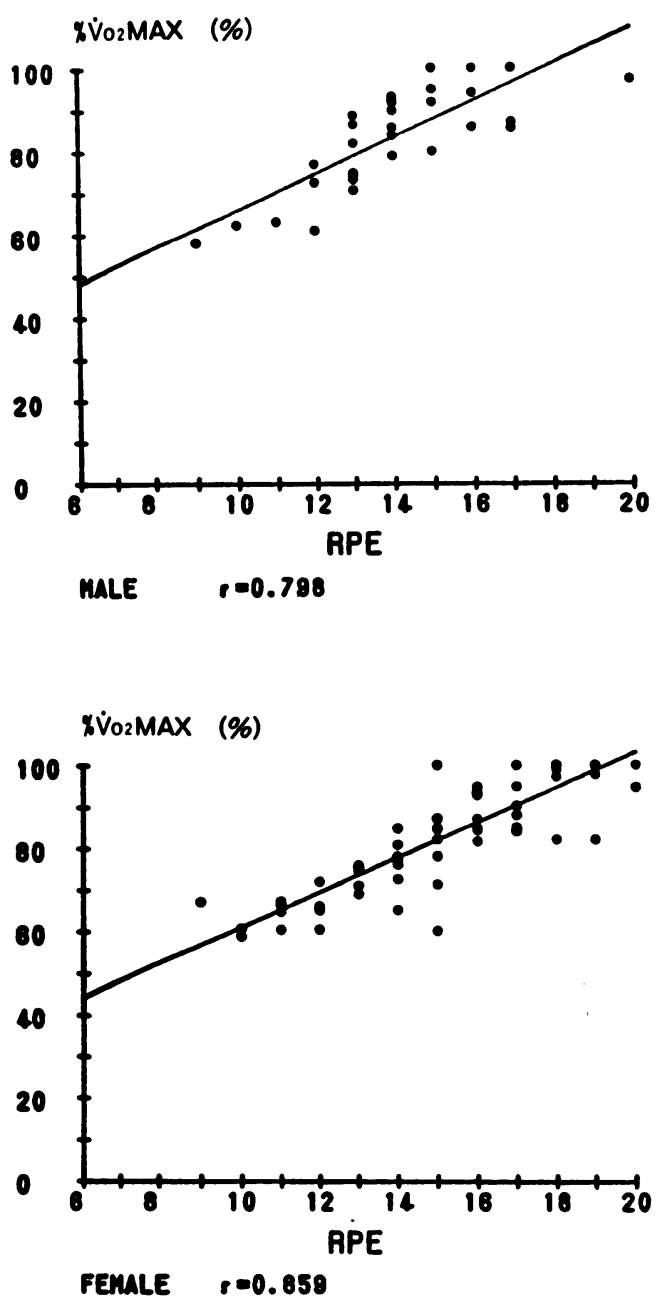

Fig. 3. The correlation between RPE and $\% \dot{\mathrm{V}}_{2} \max$ in senior citizens.

percentage of maximum oxygen intake, watt units, systolic blood pressure, respiratory frequency, METS, ventialtion, and double product. The significance of the variables in RPE for the males (from high to low) was $\% \dot{\mathrm{V}}_{2} \max$, $\% \mathrm{HRmax}$, respiratory frequency, heart rate and $\dot{\mathrm{V}}_{2}$. For the female group (from high to low), it was in the order of \% HRmax, $\dot{\mathrm{V}}_{2} \max$, heart rate, and double product. The correlation coefficient for RPE and watt units for the men was $r=0.64(p<0.01)$ and for the women $r=$ $0.63(p<0.01)$. There were no significant dif- 


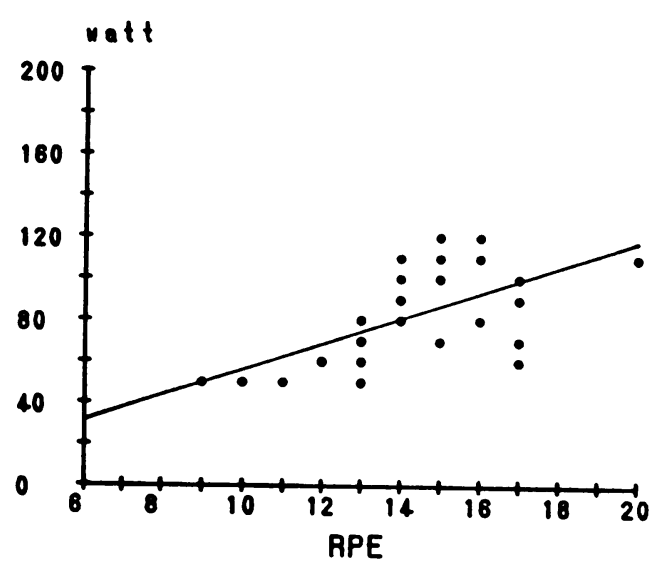

MALE $\quad r=0.637$

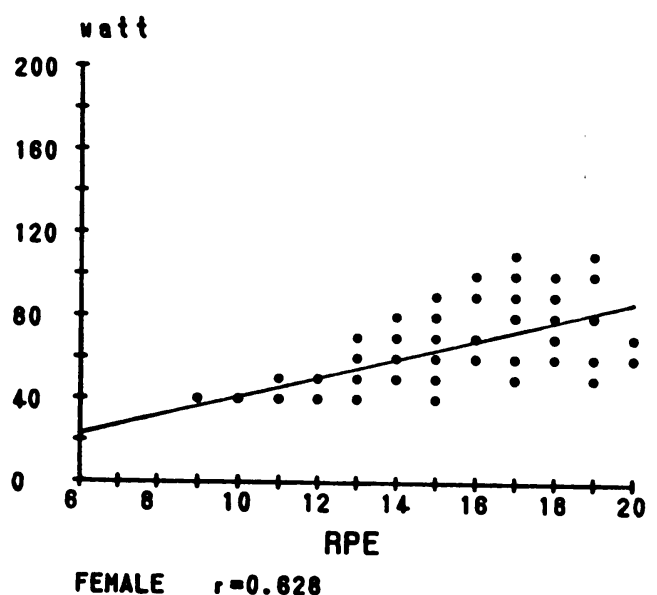

Fig. 4. The correlation between RPE and wark load exerted in terms of watt units.

ferences between RPE and systolic blood pressure.

\section{Discussion}

\section{A. The Effectiveness of RPE}

Due to the language barrier and other cultural factors, Onodera modified and translated Borg's original RPE scale for the Japanese. Using Onodera's version, the results of the younger group was analyzed. The correlation coefficient of RPE and heart rate for the younger group was $r=0.83$; with $\mathrm{RPE}$ and $\%$ HRmax it was $r=0.91$; and for RPE and
$\% \dot{\mathrm{V}}_{\mathrm{O}_{2}} \max$ it was $\mathrm{r}=0.86$. Borg \& Linderhom ${ }^{3)}$, Bar-or et al. ${ }^{11}$, and Skinner et al. ${ }^{8)}$ also showed a correlation coefficient for RPE and heart rate of $r=0.70 \sim 0.90$. For the Japanese senior citizens participating with the bicycle ergometer ; however, relationships of RPE with heart rate, $\% \dot{\mathrm{V}}_{2} \max$, and the exercise intensity in terms of watt units were $r=0.60 \sim 0.90$.

For the second trial, a high reliability was shown for males $r=0.76$ and females $r=0.90$. From these results, the exercise prescription for senior citizens showed that not only the heart rate, the $\% \dot{\mathrm{V}}_{2} \max$, or even watt units are effective but they are effective criteria.

In Fig. 5, the comparison for RPE and $\% \dot{\mathrm{V}}_{\mathrm{O}_{2}} \max$ between Onodera and this study is shown. Based on the regression equation of Onodera's results, the results of this study showed a lower RPE for the sample point of $\% \mathrm{Vo}_{2} \max$. These differences in the percentage of oxygen intake could be explained in two ways. For one, the protocol of Onodera's experiment was slightly different from that of the present experiment (i. e., age groups, physiological variables, etc...). As an example, Onodera tested a group of younger subjects, whereas this study tested a group of senior citizens. Secondly, an exact determining factor was not conclusive; therefore, it will be necessary to do further research in this area.

\section{B. The Relationship Between RPE and} Physiological Variables

With the exception of the systolic blood pressure, all other variables showed a significant difference. This was especially true for the $\dot{\mathrm{V}}_{2}, \% \dot{\mathrm{V}}_{2} \max$, watt units, respiratory frequency, METS, ventilation and double product. Within this group of variables, those that attained a high significant difference were $\% \dot{\mathrm{V}}_{2} \max$ and \% HRmax. As a result, instead of using an absolute value with greater varia- 
Table 2. The estimated of heart rate, $\% \dot{\mathrm{V}}_{2} \max$, watt units from the scale of Rating Perceived Exertion(RPE).

\begin{tabular}{|c|c|c|c|c|c|c|c|}
\hline \multicolumn{2}{|l|}{$\operatorname{sex}$} & male & female & male & female & male & female \\
\hline \multicolumn{2}{|l|}{ RPE } & \multicolumn{2}{|c|}{$\% \dot{\mathrm{V}} \mathrm{o}_{2} \max (\%)$} & \multicolumn{2}{|c|}{ HR (beat $/ \mathrm{min}$ ) } & \multicolumn{2}{|c|}{ watt } \\
\hline & 20 & 109.8 & 103.1 & 147.5 & 159.6 & 117.8 & 87.1 \\
\hline \multirow{2}{*}{ Very very hard } & 19 & 105.4 & 98.9 & 142.2 & 154.0 & 111.7 & 82.5 \\
\hline & 18 & 101.0 & 94.7 & 137.0 & 148.4 & 105.5 & 77.9 \\
\hline \multirow[t]{2}{*}{ Very hard } & 17 & 96.6 & 90.5 & 131.7 & 142.7 & 99.3 & 73.3 \\
\hline & 16 & 92.2 & 86.2 & 126.4 & 137.1 & 93.2 & 68.7 \\
\hline \multirow[t]{2}{*}{ Hard } & 15 & 87.8 & 82.0 & 121.2 & 131.5 & 87.0 & 64.1 \\
\hline & 14 & 83.4 & 77.8 & 115.9 & 125.8 & 80.8 & 59.5 \\
\hline \multirow[t]{2}{*}{ Somewhat hard } & 13 & 79.0 & 73.6 & 110.6 & 120.2 & 74.6 & 54.9 \\
\hline & 12 & 74.6 & 69.4 & 105.4 & 114.5 & 68.4 & 50.3 \\
\hline \multirow[t]{2}{*}{ Fairly light } & 11 & 70.2 & 65.2 & 100.1 & 108.9 & 62.2 & 45.7 \\
\hline & 10 & 65.8 & 61.0 & 94.8 & 103.3 & 56.1 & 41.1 \\
\hline \multirow[t]{2}{*}{ Very light } & 9 & 61.4 & 56.8 & 89.6 & 97.6 & 49.9 & 36.5 \\
\hline & 8 & 57.0 & 52.6 & 84.3 & 92.0 & 43.7 & 31.9 \\
\hline \multirow[t]{2}{*}{ Very very light } & 7 & 52.6 & 48.4 & 79.1 & 86.3 & 37.5 & 27.3 \\
\hline & 6 & 48.2 & 44.2 & 73.8 & 80.7 & 31.3 & 22.7 \\
\hline
\end{tabular}

Table 3. Zero-order Correlations of RPE with physiological variables in senior citizen male and female groups.

\begin{tabular}{l|cc|cc}
\hline \multicolumn{1}{c|}{ variables } & male & \multicolumn{2}{|c}{ female } \\
\hline Heart rate (HR), best/min & 0.691 & $* *$ & 0.790 & $* *$ \\
$\% \mathrm{HRmax}, \%$ & 0.735 & $* *$ & 0.888 & $* *$ \\
Oxygen consumption $\left(\dot{\mathrm{V}} \mathrm{O}_{2} \mathrm{max}\right), \mathrm{m} l / \mathrm{kg}^{\prime} \mathrm{min}^{-1}$ & 0.661 & $* *$ & 0.547 & $* *$ \\
$\%$ Vं $\mathrm{O}_{2} \mathrm{max} \%$ & 0.799 & $* *$ & 0.860 & $* *$ \\
Work load exerted in terms of watt, watt & 0.637 & $* *$ & 0.628 & $* *$ \\
t Systolic pressure, $\mathrm{mmHg}$ & 0.218 & $\mathrm{~N} . \mathrm{S}$ & 0.317 & $\mathrm{~N} . \mathrm{S}$ \\
Respiratory frequency, beat/min & 0.718 & $* *$ & 0.536 & $* *$ \\
METS & 0.651 & $* *$ & 0.591 & $* *$ \\
Minute ventilation, $\mathrm{m} l / \mathrm{min}$ & 0.513 & $* *$ & 0.476 & $* *$ \\
Double product & 0.508 & $* *$ & 0.691 & $* *$ \\
\hline
\end{tabular}

** : Significance at the 0.01 level

bility, the relative value that had a higher correlation with RPE was used. Borg et al. and Onodera \& Miyashita also showed similar results in their works.

When analyzing the relationship between RPE and blood pressure, data from the subjects who were at the median age or older used. In this study, only the systolic blood pressure was used to compile the data. The reason diastolic blood pressure was not used was because during the testing interference was apparent and a stable data could not be obtained. Since the diastolic blood pressure was erratic, it was proven statistically to have no reliability for our analysis. It was also shown the RPE and blood pressure showed no significance for the correlation coefficient for either the men or the women groups. Therefore, for our purpose only 
the systolic and not the diastolic was used for analysis.

In the review of literature, it has been often

\section{RPE}

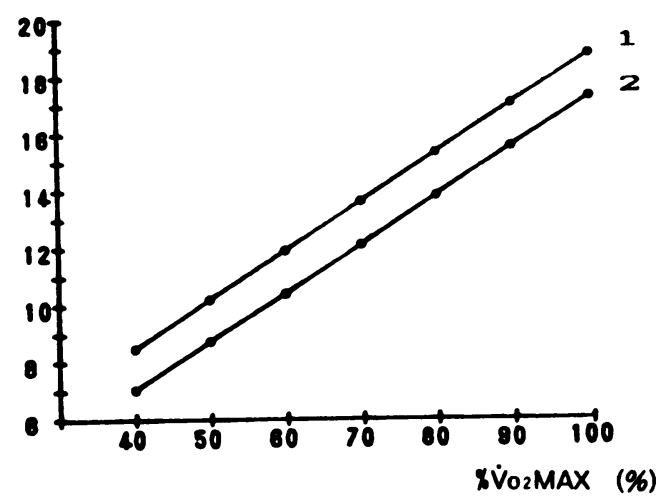

$1:$ Onodera's results

2 : present study

Fig. 5. A comparison of Onodera's RPE results with the RPE results from this experiment. stated that in the case of senior citizen subjects, particular attention must be paid to the blood pressure instead of the heart rate $^{5,12}$. This similar warning was found in Fig. 6

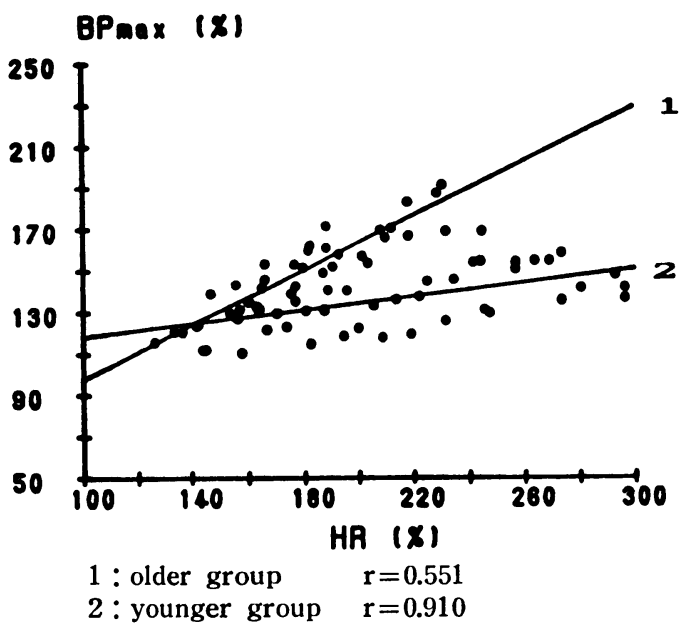

Fig. 6. Percentage of exercise exertion and rest period.

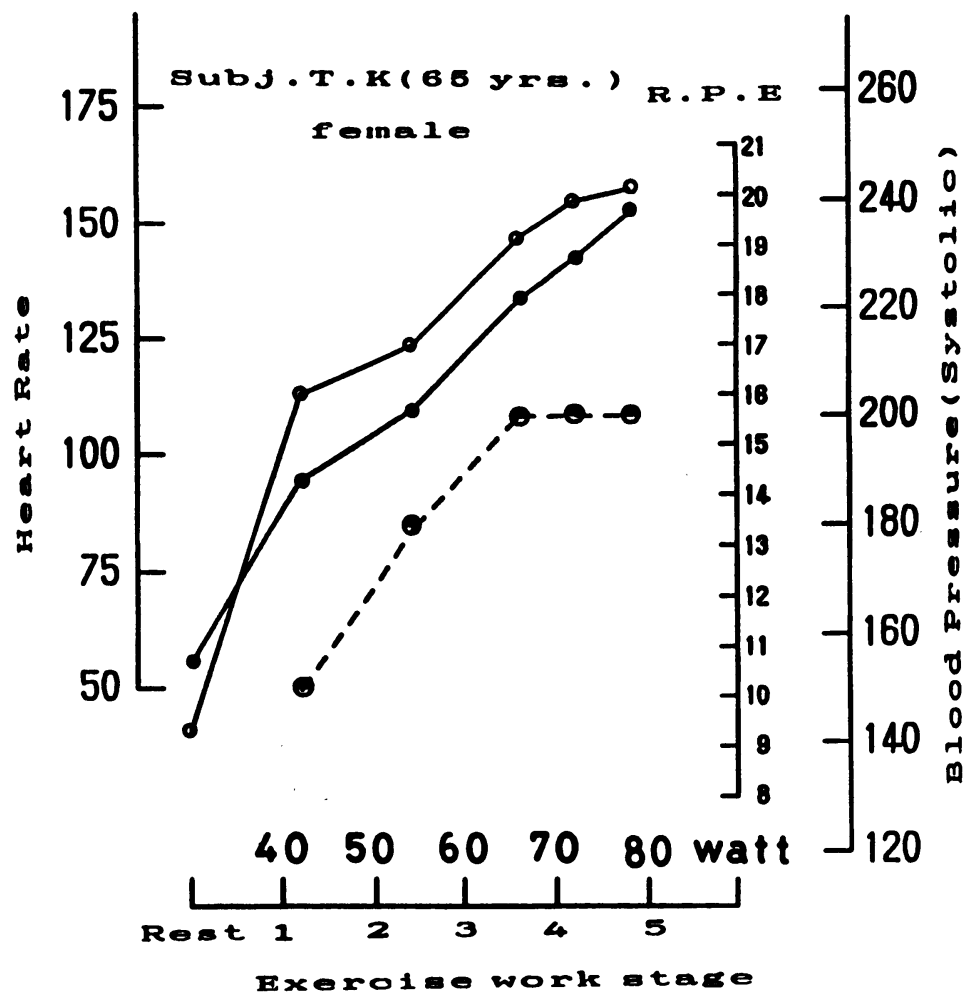

Fig. 7. An example of senior citizens subjects and thier level of RPE. 
where it shows a high percentage of blood pressure than the heart rate for exercise exertion/rest period. This could have been the result of the individual subjects whose perceived exertion greatly differs from statistical data. If this is true, it will explain why individual perceived exertion and the blood pressure correlation is not linear. Since the majority of the subjects are not personally aware of their own physical fitness and especially their point of exhaustion, it will be best kept in mind during analysis that the scale between the senior citizen subjects and the actual data may differ greatly. Therefore, since RPE is effective in training and there are no correlation between RPE and blood pressure, RPE, the heart rate and oxygen intake should be used in its place.

Overall, the results of RPE and physiological exercise intensity along with exercise intensity in terms of watt units were found to be statistically correlated. There are, however, a cultural factor that might have influenced the results.

In Fig. 7, the exercise of senior citizens are shown. As expected, the systolic blood pressure and the heart rate increased as the wattage increased. In the beginning RPE also gradually increased but then at a certain point RPE levels off and sustains a plateau even though the blood pressure and the heart rate continues to increase. This leveling of RPE could be due to psychological factors. In the case of the Japanese subjects "ganbari" could be an influential factor. A "ganbari" is a language that will give it his all and is unwilling to stop or admit his true level of exhaustion. Even Morgan ${ }^{6)}$ reported that there are certain psychological factors that influence perceived exertion. Therefore, it is advisable to have some training background in the usage of the RPE scale. The more experienced the subjects have in using the RPE scale, the better they will become in identifying their true exertion point. This has been true in our experiment with subjects who are highly physically fit and often push themselves too hard.

Finally, the effectiveness of RPE and the exercise prescription of exercise intensity has been determined. There are, however, other influencing factors that may effect the results of this study. Factors such as the style of exercise or the time duration of the exercise could be a possible determinant variable for this experiment. Since individual characteristics vary from subject to subject, a standard should be established for further research. It is also best to keep in mind that when testing older subjects, blood pressure plays an impor tant role in exercise ; however, since a correlation between RPE and systolic blood pressure was not evident, this does not mean that RPE has no effect at all on blood pressure. It simply means that the correlation between RPE and blood pressure should be closely watched.

(A portion of this research was funded by the Ministry of Education)

\section{Acknowledgments}

First of all we would like to thank the senior citizens who graciously participated in our project. Secondly, we are grateful to Dr. Tetsu Hozumi of Nagoya City University for his helpful advice. And finally, we are indebted to Mrs. Jo A. Kozuma of Kinki University for her help in the translation of this paper.

(Received, Oct. 17. 1987)

\section{References}

1) Bar-Or, O., Skinner, J., Buskirk, E. R. and Borg, G. (1972) : Physiological and perceptual indica- 
tros of physical stress in 41 to 60 years old men who vary in conditioning level and in body fatness. Med. Sci. Sports. 4, 96-100.

2) Borg, G. (1973) : Rerceived exertion: A not on "history" and method. Med. Sci. Sports. 5(2), 9093.

3) Borg, G. and Linderholm, H. (1967) : Performance exertion and pulse rate during graded exercise in various age groups. Acta. Med. Scand. Suppl. 472, 194-206.

4) Grimby, G. (1972) : Work capacity and physiologic responses to work. Amer. J. Cardiol. 30, 3742.

5) Masuda, M., Shibayama, H. and Ebashi, H.(1965): A study on the optimum doses of physical exercise for middle and elder aged from the view point of circularespiratory functions. Bull. Phy. Fit. Research Inst. 6, 55-72.

6) Morgan, W. P. (1973) : Psychological factors influencing perceived exertion. Med. Sci. Sports. 5(2), 97-103.

7) Onodera, Y. and Miyashita, M. (1976): A study on the Japanese Scale for rating of perceived exertion in endurance. J. J. of Phys. Ed. 21(4),
191-203.

8) Sidney, K. H. and Shepard, J. (1977) : Perception of exertion in the elderly. Effects of aging, mode of exercise and training. Percpt. Motor Skills. 44, 999-1010.

9) Skinner, J. S., Hutsler, R., Bergsteinova, V. and Buskirk, E. R. (1973): The validity and reliability of a rating scale of perceived exertion. Med. Sci. Sports. 5, 94-96.

10) Takeshima, N. (1987): The exercise for middle and old age citizens: A survey of a self health test and analyzing senior citizens who participated in the University volunteer sports program. 33 rd Tokai Public Health Conference Symposium, Presentation. 26-27.

11) Tokuda, T., Maruyama, H., Akiyama, S., Nakayama, A., Ikeya, Y. and Takashima, T. (1982) : Perceived exertion and heart rate in relation to age. J. J. Human Ergol. 18(5), 277-280.

12) Tokuda, T., Maruyama, H., Akiyama, S., Nakayama, A., Ikeya, Y. and Takashima, T. (1983) : Sex and age characteristics of circulatory function to exercise. J. J. Human Ergol. 19(1), 51 59. 